\title{
The assimilation of sulfur from multiple sources and its correlation with expression of the sulfate-starvation-induced stimulon in Pseudomonas putida S-313
}

\author{
Stefan Beil, $†$ Michael A. Kertesz, Thomas Leisinger \\ and Alasdair M. Cook $\ddagger$
}

Author for correspondence: Alasdair M. Cook (in Konstanz). Tel: +49 7531 884247. Fax: + 497531882966. e-mail: Alasdair.Cook@uni-konstanz.de

Institute of Microbiology, Swiss Federal Institute of Technology, $\mathrm{CH}-8092$ Zürich, Switzerland
Conditions were optimized for the batch growth of Pseudomonas putida S-313 under sulfur-limited conditions. P. putida grew exponentially with sulfate as the sole source of sulfur, and growth was concomitant with the utilization of sulfate until it was exhausted. A further $20 \%$ of protein was synthesized after the apparent disappearance of sulfate. A mass balance for the utilized sulfate in cell material was calculated, given the observed molar growth yield of about $3.6 \mathrm{~kg}$ protein $(\mathrm{mol} \mathrm{S})^{-1}$ and a sulfur content of $0.41 \% \mathrm{~S}$ in dry matter. Similar data were obtained for growth with cysteine and thiocyanate. The organism also grew exponentially with 4-toluenesulfonate (TS) as sulfur source, essentially as observed with sulfate, except that negligible protein formation after exhaustion of TS was observed. Similar data were also obtained with 4-nitrocatecholsulfate (NCS) and ethanesulfonate. Any substrate pair selected from sulfate, cysteine and thiocyanate was utilized simultaneously, and although one of the pair of substrates was always preferred, growth continued at the same rate when only one substrate remained. Growth after substrate exhaustion was observed. Any substrate pair selected from TS, NCS and ethanesulfonate gave similar data, but with less growth after exhaustion of the sulfur sources. If a mixed substrate pair was chosen from the two groups, the sulfur source from the first-named group was initially used exclusively, and the second source of sulfur was utilized subsequently, after a lag phase. The data are considered to reflect the control of scavenging for sulfur and of distribution of sulfur in the cell exerted by the sulfate-starvation-induced stimulon [Kertesz, Leisinger \& Cook, J Bacteriol (1993) 175, 1187-1189].

Keywords: Pseudomonas putida, sulfate-starvation-induced stimulon, sulfur metabolism, desulfonation, arylsulfatase

\section{INTRODUCTION}

It has been known for 40 years that the assimilation of sulfur into the bacterial cell, especially in Escherichia coli, and its distribution amongst cellular constituents, are

tPresent address: National Research Center for Biotechnology, Mascheroder Weg 1, D-38124 Braunschweig, Germany.

$\ddagger$ Present address: Faculty of Biology, University of Konstanz, Postfach 5560 M649, D-78434 Konstanz, Germany.

Abbreviations: SSIS, sulfate-starvation-induced stimulon; TS, p-toluenesulfonate; NCS, 4-nitrocatecholsulfate. subject to regulation (Roberts et al., 1955). Since the supply of sulfur to a bacterial cell may vary both qualitatively and quantitatively, bacteria need to be able to switch efficiently between preferred sources of sulfur (e.g. cysteine and sulfate) and other sulfur-containing compounds (e.g. cysteic acid and taurine). Growth under sulfur-limited conditions leads to the redistribution of cellular sulfur, with the effective disappearance of small sulfur-containing molecules and of alcohol-soluble protein, which constitute about $40 \%$ of the total sulfur in cells of E. coli supplied with excess sulfate (Roberts $e t$ al., 1955). An understanding of how bacteria sense, and react 
to, changes in the sulfur status of their environment has advanced only slowly (Harder \& Dijkhuizen, 1983), though evidence that the regulatory phenomenon is widespread has been obtained (e.g. Kayser et al., 1993; Seitz et al., 1993; Uria-Nickelsen et al., 1993a, b; Zürrer et al., 1987).

The description of preferred sulfur sources for E. coli by Roberts et al. (1955) was written at a time prior to the development of the operon theory. Since that time, however, global regulatory networks for the assimilation of carbon, nitrogen and phosphorus have been well characterized and are to be found in standard textbooks (e.g. Neidhardt, 1987). One such network associated with sulfur metabolism, the cys regulon (Kredich, 1992), is also well known. In addition, E. coli and several other species of bacteria synthesize a number of proteins whose synthesis is co-ordinately suppressed during growth with 'preferred' sulfur sources, and enabled when other sulfur sources are provided, and which do not form part of the known cys regulon (Kertesz et al., 1993). We consider these proteins to be a phenotype of the sulfate-starvationinduced stimulon, SSIS. As in the earlier experiments (Roberts $e t$ al., 1955) sulfur sources used for growth could be divided into two groups: sulfur-containing substrates which suppress synthesis of the SSIS proteins (sulfate, cysteine and a few species-specific additions), and substrates which lead to expression of the SSIS, referred to below as SSI substrates (all other sulfur sources tested).

A major problem experienced by many groups working with sulfur limitation in bacteria is quantification of low levels of the substrates, especially inorganic sulfate (Roberts et al., 1955; Seitz et al., 1993; Uria-Nickelsen et al., 1993a). Researchers have been limited to the use of the few ${ }^{35}$ S-labelled compounds available, and very few accurate and complete growth kinetics have therefore been reported. In recent years, however, ion chromatography has become available to facilitate analysis of sulfate utilization during sulfate-limited growth (Wanner \& Egli, 1990), and when additional sulfur sources such as arylsulfonates (Kertesz et al., 1994b; Zürrer et al., 1987) or aromatic sulfur esters (Dodgson et al., 1982) can be used by the bacterial species under study (e.g. by pseudomonads), these too may be measured directly.

Here we present detailed kinetics of the growth of Pseudomonas putida in the presence of a single source of sulfur or of pairs of sources belonging to the non-SSI group, the SSI group or both, and a rationalization of these and other data in terms of the SSIS.

\section{METHODS}

Organism, growth media and cultivation. Pseudomonas putida S-313 (DSM 6884) (Busse et al., 1989; Zürrer et al., 1987) was grown in a sulfate-free minimal medium similar to that previously described (Kertesz et al., 1993), but containing sodium acetate $(50 \mathrm{mM})$ instead of sodium succinate as carbon and energy source. Sulfur sources were added as described in the text. Routinely, the organism was cultivated in Erlenmeyer flasks at $30^{\circ} \mathrm{C}$ on an orbital shaker (180 r.p.m.), and growth was monitored as $\mathrm{OD}_{650}$.
Detailed growth experiments were carried out in an apparatus designed for controlled batch culture of bacteria (Harvey et al., 1968). A preculture from the exponential growth phase $(100 \mu \mathrm{g}$ protein $\left.\mathrm{ml}^{-1}\right)$ was inoculated $(3-5 \%, \mathrm{v} / \mathrm{v})$ into $500 \mathrm{ml}$ minimal medium in flat-bottomed 1 litre side-arm flasks in a thermostatted water bath at $30^{\circ} \mathrm{C}$. Each culture was vigorously mixed by a magnetically-driven stirring-bar and sterile air was supplied at a rate of $250 \mathrm{ml} \mathrm{min}^{-1}$. A multiple-place stirrer accommodating up to six flasks was used, allowing several cultures to be analysed simultaneously, under identical conditions.

HPLC determination of aromatic sulfonates, sulfates, and phenols. HPLC was done on Nucleosil- $C_{18}$ reversed-phase columns $(250 \times 4.6 \mathrm{~mm}$; particle size $7 \mu \mathrm{m})$. The mobile phase used was $100 \mathrm{mM}$ potassium phosphate, $\mathrm{pH} 6.7$, with appropriate amounts of methanol $(0-80 \%, \mathrm{v} / \mathrm{v})$. Compounds eluting from the column were detected spectrophotometrically at $200 \mathrm{~nm}$ and at $220 \mathrm{~nm}$ ( $p$-toluenesulfonate and $p$-cresol) or $420 \mathrm{~nm}$ (nitrocatecholsulfate, nitrocatechol), and could be detected down to $0 \cdot 2 \mu \mathrm{M}$.

Determination of sulfate and thiocyanate. Inorganic sulfate and thiocyanate were accurately quantified by ion chromatography with chemical suppression and conductimetric detection after separation on an anion-exchange column (AS9 column with an AG9 guard column; Dionex). The compounds were eluted isocratically with $1.8 \mathrm{mM} \mathrm{Na}_{2} \mathrm{CO}_{3} / 1.6 \mathrm{mM} \mathrm{NaHCO}_{3}$ for simultaneous detection of sulfate and thiocyanate, or with $3 \mathrm{mM}$ $\mathrm{Na}_{2} \mathrm{CO}_{3}$ for quantification of thiocyanate alone. The detection limit for both these compounds was $0.2 \mu \mathrm{M}$, with accurate quantification possible above $1 \mu \mathrm{M}$. Thiocyanate was also assayed by the colorimetric method of Sörbo (1955), but this assay was found to be inaccurate at thiocyanate concentrations below $10 \mu \mathrm{M}$, and to suffer interference from compounds present in spent growth medium.

Determination of cysteine. Cysteine was quantified by reversed-phase HPLC following conversion to its $S$-carboxymethyl- $N$-(2,4-dinitrophenyl) derivative (Fariss \& Reed, 1987; Reed et al., 1980). Samples $(1 \mathrm{ml})$ were deproteinized by overnight treatment with trichloroacetic acid $(0.5 \mathrm{M})$ at $-20^{\circ} \mathrm{C}$, followed by centrifugation in a microcentrifuge at $4{ }^{\circ} \mathrm{C}$. The supernatant was then derivatized by sequential reaction with iodoacetic acid and 1-fluoro-2,4-dinitrophenylbenzene, as described by Fariss \& Reed (1987). Derivatized cysteine was quantified after separation with a mobile phase of $10 \mathrm{mM}$ potassium phosphate, $\mathrm{pH} 2 \cdot 2$, and a methanol gradient $(0-80 \%$, $\mathrm{v} / \mathrm{v})$. Compounds were detected spectrophotometrically at $200 \mathrm{~nm}$ and $365 \mathrm{~nm}$. The detection limit for cysteine was $0 \cdot 2 \mu \mathrm{M}$.

Other procedures. Total protein in cell suspensions was determined by a modified Lowry method (Kennedy \& Fewson, 1968) with bovine serum albumin as standard. Measurements of total cell sulfur were carried out on lyophilized cells by total oxidation with hydrogen peroxide, followed by ion chromatographic analysis of the sulfate produced. All glassware used in sulfate-limited experiments was washed with $3 \mathrm{M} \mathrm{HCl}$ and rinsed thoroughly with distilled water before use.

\section{RESULTS}

\section{Batch growth of $P$. putida S-313 under sulfur-limiting conditions}

In preliminary experiments, $P$. putida S-313 was grown with an excess of sulfur source $(200 \mu \mathrm{M}$, see below) in $5-50 \mathrm{ml}$ liquid cultures in closed $300 \mathrm{ml}$ screw-capped 

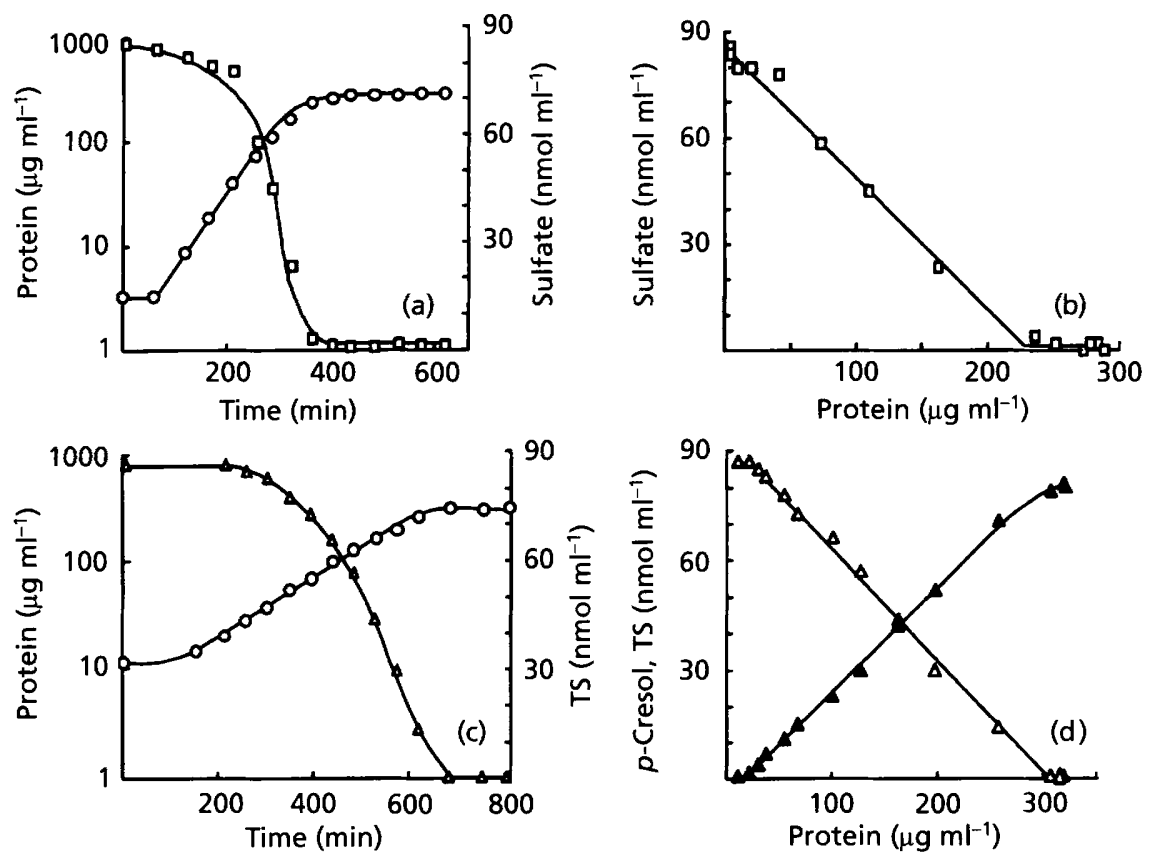

Fig. 1. Growth of $P$. putida $S-313$ with limiting sulfate $(a, b)$ or TS $(c, d)$ as sole added source of sulfur in acetate-minimal medium. Growth is depicted as a function of time $(a, c)$ and as a function of substrate utilization (b, $d)$. The inoculum for the sulfate-limited culture was from a growing sulfate-limited culture, that for the TS-limited culture was from a growing TS-limited culture. The kinetic plot in (c) is drawn without the values for $p$-cresol in order to simplify the figure. $\square$. Sulfate; $\triangle$, TS; $\boldsymbol{\Delta}, p$-cresol; O. protein.

Erlenmeyer flasks. These conditions have been used in the past in order to avoid contamination by airborne sulfur. On closer examination, however, we found that the final growth yield obtained was significantly lower under these conditions than when the cells were grown in side-arm flasks containing vigorously stirred media aerated from a source of compressed air (Harvey et al., 1968), and that yields with toluenesulfonate (TS) were lower than those obtained with sulfate. Since it was important for this study to have a complete mass balance for all sulfur sources used, we chose to use the more highly aerated system for further work.

The conditions under which the growth of P. putida was terminated by the exhaustion of the available sulfur were examined with inorganic sulfate and TS, which represent sulfur sources that lead to suppression and expression of the SSIS, respectively (Kertesz et al., 1993). Sulfur was growth-yield-limiting up to at least $80 \mu \mathrm{M}$ TS or $100 \mu \mathrm{M}$ sulfate, so we routinely used a total added sulfur concentration of $80 \mu \mathrm{M}$ in our experiments. In experiments with two sulfur sources, each was added at $40 \mu \mathrm{M}$ concentration. It is important to note that because we worked with batch cultures, we use the term 'growthlimiting' exclusively to refer to substrate concentrations which lead to termination of growth, and not to concentrations under which the rate of growth is limited (which is the usual terminology with continuous cultures) (Mason \& Egli, 1993). Below the growth-limiting concentrations, the growth yield was directly proportional to the amount of sulfur supplied, and the molar growth yield was about
$3.6 \mathrm{~kg}$ protein $(\mathrm{mol} \mathrm{S})^{-1}$. In the absence of added sulfur, we observed growth corresponding to the presence of about $5 \mu \mathrm{M}$ sulfate. This value is similar to those observed elsewhere in 'sulfur-free' mineral media (Roberts $t$ al., 1955; Seitz et al., 1993; Zürrer et al., 1987), which suggests that the air supply was free of sulfur. The growth yield thus indicated an essentially complete mass balance of sulfur in protein (see Discussion).

\section{Growth and product formation from a single sulfur source}

Growth kinetics were examined with three single sulfur sources: sulfate, TS and 4-nitrocatecholsulfate (NCS). Complete utilization of the sulfur source to give the standard molar growth yield was observed in each case, and for the latter two compounds effectively stoichiometric conversion to the corresponding desulfurized product was also observed ( $97 \%$ yield of nitrocatechol from NCS, $95 \%$ yield of cresol from TS). The growth rate was the same for sulfate and for NCS, but was slower with TS. However, it is not known whether the ratelimiting factor here is substrate transport, oxygen concentration, or the desulfonation reaction itself.

When growth was examined in detail, a more complex pattern was discerned (Fig. 1). P. putida S-313 initially grew exponentially $\left(\mu=0.69 \mathrm{~h}^{-1}\right)$ until sulfate disappeared from the medium (Fig. 1a). After sulfate disappeared, however, growth continued at a decreasing rate and $19 \%$ of the overall protein synthesis occurred after 

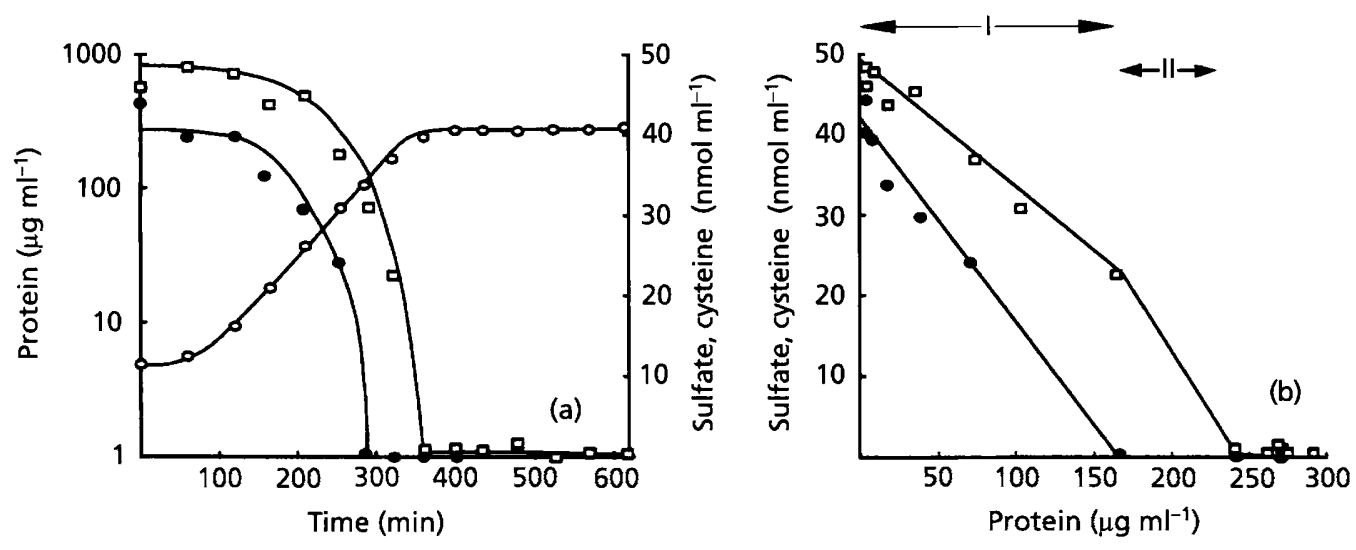

Fig. 2. Growth of $P$. putida $S-313$ with sulfate and cysteine as paired limiting source of sulfur in acetate-minimal medium. Growth is depicted as a function of time (a) and as a function of substrate utilization (b). The inoculum was from a growing sulfate-limited culture. Growth phases I and II are indicated. $\square$, Sulfate; 0 , cysteine; 0 , protein.
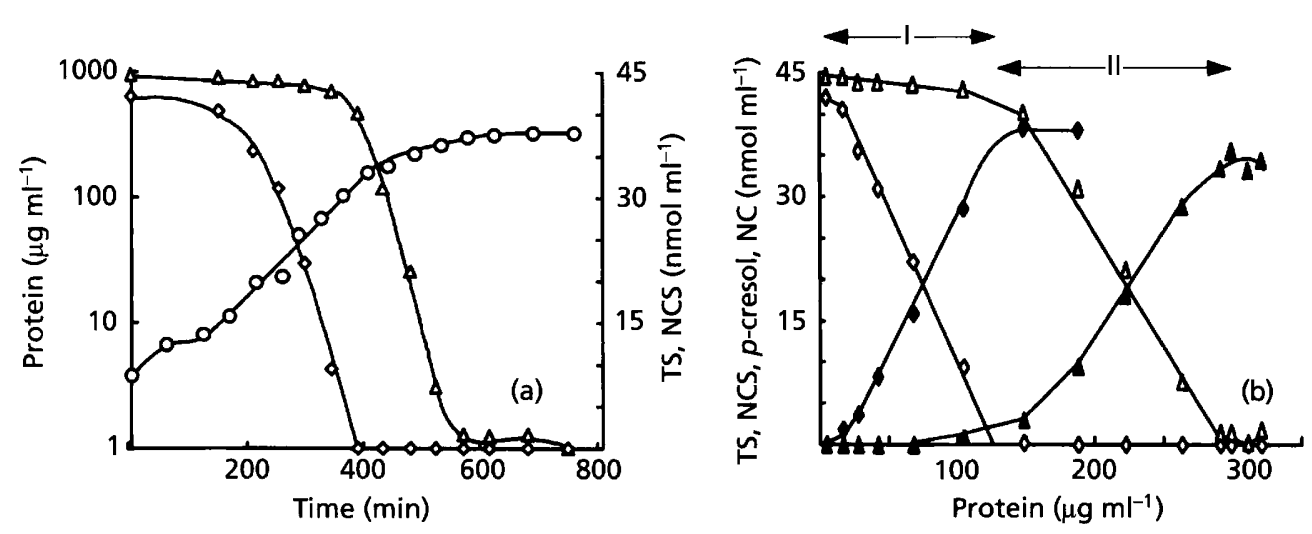

Fig. 3. Growth of $P$. putida S-313 with TS and NCS as paired limiting source of sulfur in acetate-minimal medium. Growth is depicted as a function of time (a) and as a function of substrate utilization (b). The inoculum was from a growing sulfate-limited culture; we presume the possible deviation from exponential growth at about 70 min to be caused by growth with contaminative sulfate and thus irrelevant to the main experiment. Growth phases I and II are indicated. The kinetic plot (a) is drawn without the values for $p$-cresol and 4-nitrocatechol in order to simplify the figure. $\triangle$, TS; $\Delta$, $p$-cresol; $\diamond$, NCS; $\bullet$, 4-nitrocatechol (NC); 0 , protein.

exhaustion of the nominal sole source of sulfur (Fig. 1b). The molar growth yield thus does not represent a single phenomenon, but a composite comprising two stages.

Strain S-313 also grew exponentially $\left(\mu=0.38 \mathrm{~h}^{-1}\right)$ with TS as the sulfur source (Fig. 1c). No delay was seen between disappearance of TS and release of the desulfonation product cresol, suggesting that no significant intracellular pool exists for either compound. For the most part, growth was concomitant with substrate utilization, and growth after the exhaustion of substrate was negligible (Fig. 1d). Growth of strain S-313 with NCS $\left(\mu=0.69 \mathrm{~h}^{-1}\right)$, while otherwise resembling growth with TS, displayed unambiguous growth $(13 \%)$ after exhaustion of NCS (not shown).

The growth curves (Figs 1-4) were largely unaffected by the inoculum used. However, sulfate-grown precultures displayed a longer lag-phase in TS- or NCS-containing medium than in sulfate-containing medium. Cells from TS-grown precultures, in contrast, grew immediately after inoculation into all media tested.

\section{Utilization of two sulfur sources during growth}

Two sulfur sources which suppress expression of SSIS. When P. putida S-313 grew with sulfate and cysteine, the two sulfur sources were utilized simultaneously, and monophasic, exponential growth was observed (Fig. 2a). Complete disappearance of each substrate was observed, but with different rates. We can thus recognize different phases in growth. Phase I lasted from inoculation until exhaustion of a preferred sulfur source, and phase II from the end of phase I to the end of growth. Cysteine was preferred to sulfate, with about $64 \%$ of the total sulfur used in phase I being derived from cysteine. Phase II comprised utilization of sulfate alone, till its exhaustion, 

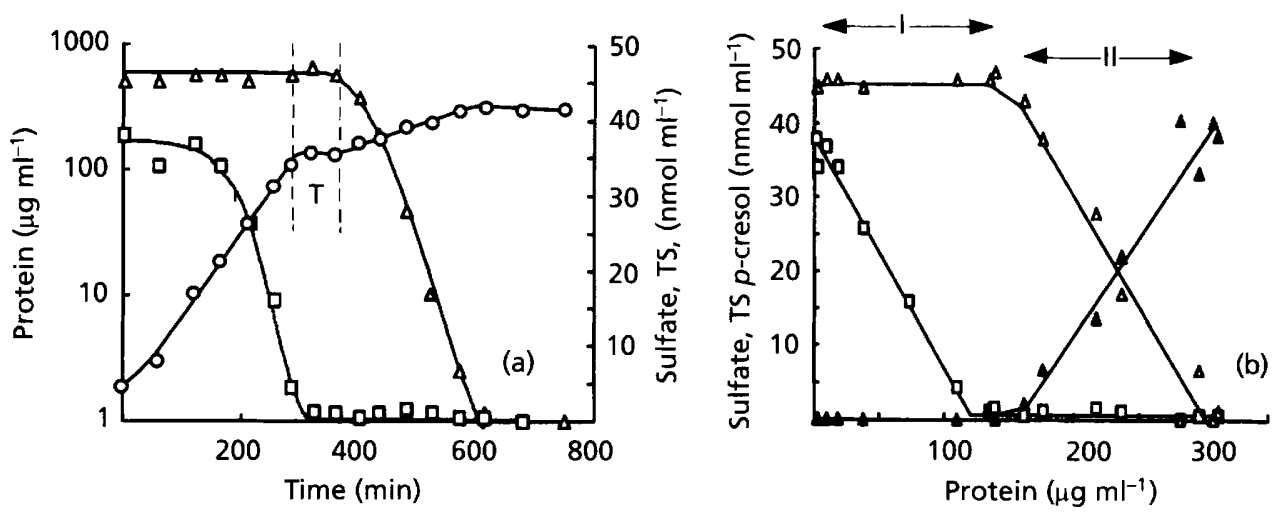

Fig. 4. Growth of $P$. putida S-313 with sulfate and TS as paired limiting source of sulfur in acetate-minimal medium. Growth is depicted as a function of time (a) and as a function of substrate utilization (b). The inoculum was from a growing sulfate-limited culture. Growth phases I and II and the transition phase ' $T$ ' between them are indicated. The kinetic plot (a) is drawn without the values for $p$-cresol in order to simplify the figure. $\square$, Sulfate; $\triangle$, TS; $\boldsymbol{\Delta}, p$-cresol; 0 , protein.

followed by slow growth in the absence of detectable sulfur sources (Fig. 2b; cf. Fig. 1b).

Identical behaviour was observed when strain S-313 grew with sulfate and thiocyanate (not shown). In this case, sulfate was the preferred substrate and phase II comprised utilization of residual thiocyanate and growth in the absence of detectable sulfur sources.

Two sulfur sources which permit expression of SSIS. When P. putida S-313 grew with TS and NCS, concurrent utilization of the two sulfur sources was observed (Fig. $3 a)$. However, the utilization rates were very different, as expected from the growth rates observed in singlesubstrate cultures (see above). Ninety-five percent of the sulfur assimilated during phase I was derived from NCS (Fig. 3a), but desulfonation of TS in phase I was also readily detected, not only as disappearance of TS, but also as formation of cresol (readily detected by HPLC but poorly represented in Fig. 3). Phase II comprised utilization of residual TS as well as some growth in the absence of detected sulfur sources.

Strain S-313 grew with a mixture of TS and ethanesulfonate, though we could not quantify the latter. From the growth curve it was clear that both substrates were utilized simultaneously during phase I, and ethanesulfonate was the preferred substrate. Phase II comprised utilization of residual TS as well as some growth in the absence of detected sulfur sources (not shown).

One substrate which suppresses and one which permits expression of SSIS. A quite different, biphasic, growth pattern was observed when strain S-313 was supplied with sulfate and TS (Fig. 4a). In this case, only sulfate was assimilated during Phase I, and TS was not utilized at all, as was confirmed by the complete absence of cresol (Fig. 4b). Phase I, ending with the exhaustion of sulfate, was separated from phase II by a transition of about $50 \mathrm{~min}$. Negligible growth was seen in phase II after exhaustion of TS. Growth was exponential in both phase I and phase II, and the growth rates corresponded to those observed with the single sulfur substrates (see above).

The same pattern of biphasic growth, with a brief halt after exhaustion of the substrate which suppresses SSIS and complete absence of TS utilization during phase I, was also observed with the substrate mixtures of TS and cysteine and of TS and thiocyanate (not shown).

\section{Growth after exhaustion of the sulfur source}

Washed cells of $P$. putida S-313 grown with excess sulfate as sulfur source had a sulfur content of $0.45 \%$ on a dry weight basis. This level decreased to $0.41 \%$ after $80 \mathrm{~min}$ of sulfur deprivation, the increase in biomass being attributed largely to protein. Comparative measurements for $E$. coli showed a much higher initial value of $1.04 \% \mathrm{~S}$, as reported previously (Roberts et al., 1955), probably due to the high intracellular content of glutathione in this species. After $40 \mathrm{~min}$ of sulfur starvation the sulfur content of E. coli cells decreased to $0.44 \%$, in agreement with earlier data (Roberts et al., 1955).

\section{DISCUSSION}

Because of the ubiquitous presence of trace amounts of sulfur in air and water, care is required in order to obtain valid data on the growth of organisms under sulfur limitation. In addition to the routine processing of laboratory glassware and equipment to minimize contamination with sulfur, we have directly quantified not only the sulfur substrates for $P$. putida $\mathrm{S}-313$ but also the products of desulfurization, using chromatographic methods (cf. Roberts et al., 1955). We have thus been able to follow accurately the whole growth curve rather than just small portions thereof (e.g. Seitz et al., 1993). This approach has given us sensitivity in observing and evaluating the biological phenomena and the mass balance for sulfur. Thus for $P$. putida with its $0.41 \%$ sulfur, i.e. $4.1 \mathrm{~g}$ sulfur ( $\mathrm{kg}$ dry weight $)^{-1}$, or $8.2 \mathrm{~g}$ sulfur $(\mathrm{kg}$ protein) ${ }^{-1}$ (cf. Luria, 1960), we balance $30 \mathrm{~g}$ of sulfur 
$(>0.9 \mathrm{~mol} ; 8.2 \times 3.6)$ in the $3.6 \mathrm{~kg}$ of protein which represent the molar growth yield. It is of note that batch growth in the presence of a yield-limiting sulfur source is exponential (Figs 1-4 and Kertesz et al., 1994b), and that growth is proportional to substrate utilization (Figs 1 and 4). It would appear that only Wanner \& Egli (1990) have previously demonstrated this, for Klebsiella pneumoniae utilizing sulfate, though there is clear evidence that Corynebacterium sp. grows exponentially in a slight excess of sulfur (Omori et al., 1992). Since the rate of growth of $P$. putida was exponential and largely independent of sulfur source (with the exception of TS), it appears that intracellular sulfur is probably not growth-rate limiting under the conditions used.

Sulfur sources for $P$. putida S-313 could be graded into various levels of 'preferred' and 'non-preferred' types. This phenomenon has previously also been reported for E. coli (Roberts et al., 1955), several enteric bacteria (UriaNickelsen et al., 1993a), Comamonas acidovorans and some soil bacteria (Seitz et al., 1993), some yeasts (UriaNickelsen et al., 1993b), Rbodococcus rbodochrous (Kayser et al., 1993) and rudimentarily for $P$. putida S-313 (Zürrer $e t$ al., 1987), but our determinations allowed us to distinguish between two critical groups of compounds. The 'preferred' sulfur sources, sulfate, cysteine and thiocyanate, are chemically and structurally diverse, and are characterized by simultaneous utilization (Fig. 2), though at differing rates. Most importantly, the presence of these 'preferred' sulfur sources prevents degradation of the second group (Fig. 4). The second group of sulfur sources, here represented by ethanesulfonate, TS and NCS, is equally diverse, is also characterized by simultaneous utilization (Fig. 3) at differing rates, and is utilized solely in the absence of chemicals in the first group. When members of the first group of substrates are absent, an entire set of new proteins (the SSIS proteins) is synthesized (Kertesz et al., 1993). The SSIS proteins include arylsulfatase (EC 3.1.6.1) (Beil et al., 1995; Kertesz et al., 1993; cf. Dodgson et al., 1982) and presumably the enzymes involved in the desulfonation of ethanesulfonate and of TS. The SSIS in different organisms is expected to comprise different ranges of enzymes (Kertesz et al., 1993), thus allowing different organisms to scavenge for different ranges of sulfur sources in the absence of sulfate [and organism-specific compounds in this group - thiocyanate, for example, is not a preferred sulfur source for E. coli (Kertesz et al., 1993)].

Regulation of sulfur assimilation by the nature of the sulfur supply has been observed elsewhere, the best characterized system being the cysteine biosynthetic pathway. Sulfate activation and transformation to cysteine are repressed both by cysteine and by sulfate, though the latter appears, at least in E. coli, to play only an indirect role, as an anti-inducer after conversion to sulfide (Kredich, 1992). However, we have found no report of thiocyanate affecting this pathway, and indeed, the mechanism by which thiocyanate sulfur is assimilated appears to be unknown. Regulation of the cysteine biosynthetic enzymes differs significantly from that of the SSIS (Fig. 4b; cf. Beil et al., 1995) in that a base level of cysteine biosynthesis is always present even during growth with 'preferred' substrates, whereas the SSIS is completely suppressed under these conditions, at least in our experience (Kertesz et al., 1993; cf. Seitz et al., 1993).

Another component of the SSIS appears to be the redistribution of sulfur between different intracellular pools, which was observed as further growth in the apparent absence of a sulfur source after substrate exhaustion. This effect is always observed after growth with sulfate (Fig. 1b) and the other group 1 compounds, and was detected in the same order of magnitude by Wanner \& Egli (1990) in their careful study. Whereas some of this redistribution can come from small molecules, as assayed radiochemically in E. coli (Roberts et al., 1955 ) and confirmed in our microanalysis of cell material, the alteration in the level of sulfur in $P$. putida S-313 before and after starvation $(0 \cdot 45$ to $0.41 \%)$ is insufficient to account for the $20 \%$ of cell protein which is synthesized under these conditions. Alterations in the protein complement of the cell are therefore required, whereby proteins of high sulfur content are replaced by others containing lower amounts of cysteine and methionine. Evidence for this phenomenon has been presented previously (Harder \& Dijkhuizen, 1983; Kertesz et al., 1994a; Roberts et al., 1955), but the most clear-cut support for the phenomenon is the expression of low-sulfur-content phycobilisomal proteins by cyanobacteria grown under sulfurlimiting conditions, and the expression of sulfur-rich proteins by the same organism under conditions of excess sulfur (Mazel \& Marlière, 1989). We thus interpret our SSIS proteins in part as replacements for high-sulfur proteins produced in the presence of excess sulfur. Indeed, if all sulfur-scavenging enzymes are all expressed as weakly as is the characterized arylsulfatase from $P$. aeruginosa (Beil et al., 1995), they will not be detected in our two-dimensional protein separations, and the strongly expressed SSIS proteins which we have previously seen (Kertesz et al., 1993) must have other functions.

The existence of the SSIS, and its regulation solely by sulfur supply and independently of carbon metabolism, can explain the surprise of some authors that the carbon moiety of their sulfur-containing substrate is not utilized (e.g. Kayser et al., 1993; Uria-Nickelsen et al., 1993a). Indeed, the ability of an organism to utilize a compound as a carbon source can be lost while its ability to utilize it as a source of sulfur is unaffected (Seitz et al., 1993). Correspondingly, an organism which utilizes an arylsulfonate as sole source of carbon and energy, and excretes the sulfur almost quantitatively into the medium, can be unable to utilize the sulfonate as a sulfur source (e.g. Thurnheer et al., 1986); the requirements for carbon and sulfur are regulated independently and different enzymes are involved. This is demonstrated in the desulfonation of benzenesulfonate as part of sulfur metabolism, where monooxygenation occurs (Zürrer et al., 1987), and in carbon metabolism, where dioxygenation occurs (Thurnheer et al., 1990).

The role of SSIS proteins in scavenging sulfur sources, coupled to their expression solely in the absence of sulfate, seems quite logical for a water-borne organism like 
Pseudomonas, because rivers and lakes normally have sulfate in excess of bacterial requirements (e.g. $70 \mu \mathrm{M}$; Ward \& Winfrey, 1985). Similarly, enterobacteria, living in a high-salt environment in water derived from natural waters, need only express SSIS proteins when the sulfate supply is exhausted. The same regulatory phenomenon in a soil bacterium (Kayser et al., 1993) seems surprising, because sulfate is scarce in soils, where sulfonates and sulfate esters make up the greatest part of the sulfur (Autry \& Fitzgerald, 1990; Fitzgerald, 1978). To elucidate this phenomenon further, further studies are continuing, to characterize the SSIS proteins from soil species on a biochemical level.

\section{ACKNOWLEDGEMENTS}

This work was supported in part by an exchange program of the Swiss Federal Institute of Technology, Zürich (S. B.) and by Swiss National Foundation grant no. 31-33963.92 (M. A. K.). Elemental analyses were done by the Microanalytical Laboratory, Organic Chemistry, ETH Zürich.

\section{REFERENCES}

Autry, A. R. \& Fitzgerald, J. W. (1990). Sulfonate S: a major form of forest soil organic sulfur. Biol Fertil Soils 10, 50-56.

Beil, S., Kehrli, H., James, P., Staudemann, W., Cook, A. M., Leisinger, T. \& Kertesz, M. A. (1995). Purification and characterization of the arylsulfatase synthesized by $P$ sendomonas aeruginosa $\mathrm{PAO}$ during growth in sulfate-free medium, and cloning of the arylsulfatase gene (ats A). Eur J Biochem 229, 385-394.

Busse, H.-J., El-Banna, T. \& Auling, G. (1989). Evaluation of different approaches for identification of xenobiotic-degrading pscudomonads. Appl Environ Microbiol 55, 1578-1583.

Dodgson, K. S., White, G. F. \& Fitzgerald, J. W. (1982). Sulfatases of Microbial Origin. Boca Raton: CRC Press.

Fariss, M. W. \& Reed, D. J. (1987). High-performance liquid chromatography of thiols and disulfides: dinitrophenol derivatives. Methods Enzymol 143, 101-109.

Fitzgerald, J. W. (1978). Naturally occurring organosulfur compounds in soil. In Sulfur in the Environment, pp. 391-443. Edited by J. O. Nriagu. New York: Wiley.

Harder, W. \& Dijkhuizen, L. (1983). Physiological responses to nutrient limitation. Annu Rev Microbiol 37, 1-23.

Harvey, N. L., Fewson, C. A. \& Holms, W. H. (1968). Apparatus for batch culture of micro-organisms. Lab Pract 17, 1134-1136.

Kayser, K. J., Bielaga-Jones, B. A., Jackowski, K., Odusan, O. \& Kilbane, J. J. (1993). Utilization of organosulfur compounds by axenic and mixed cultures of Rbodococcus rhodochrous IGTS8. J Gen Microbiol 139, 3123-3129.

Kennedy, S. I. T. \& Fewson, C. A. (1968). Enzymes of the mandelate pathway in bacterium N.C.I.B. 8250. Biochem J 107, 497-506.

Kertesz, M A., Leisinger, T. \& Cook, A. M. (1993). Proteins induced by sulfate limitation in Escherichia coli, Pseudomonas putida, or Stapbylococcus aureus. J Bacteriol 175, 1187-1190.

Kertesz, M. A., Cook, A. M. \& Leisinger, T. (1994a). Microbial metabolism of sulfur- and phosphorus-containing xenobiotics and its regulation. FEMS Microbiol Ret 15, 195-215.

Kertesz, M. A., Kölbener, P., Stockinger, H., Beil, S. \& Cook, A. M. (1994b). Desulfonation of linear alkylbenzenesulfonate (LAS) surfactants and related compounds by bacteria. Appl Environ Microbiol 60, 2296-2303.

Kredich, N. M. (1992). The molecular basis for positive regulation of cys promotors in Salmonella typhimurium and Escherichia coli. Mol Microbiol 6, 2747-2753.

Luria, S. E. (1960). The bacterial protoplasm: composition and organization. In The Bacteria, vol. 1, pp. 1-34.

Mason, C. A. \& Egli, T. (1993). Dynamics of microbial growth in the decelerating and stationary phase of batch culture. In Starvation in Bacteria, pp. 81-102. Edited by S. Kjelleberg. New York: Plenum Press.

Mazel, D. \& Marlière, P. (1989). Adaptive eradication of methionine and cysteine from bacterial light-harvesting proteins. Nature 341, 245-248.

Neidhardt, F. C. (1987). Multigene systems and regulons. In Escherichica coli and Salmonella typhimurium: Cellular and Molecular Biology, pp. 1313-1317. Edited by F. C. Neidhardt, J. L. Ingraham, K. Brooks Low, B. Magasanik, M. Schaechter \& H. E. Umbarger. Washington: American Society for Microbiology.

Omori, T., Monna, L., Saiki, Y. \& Kodama, T. (1992). Desulfuration of dibenzothiophene by Corynebacterium sp. strain SY1. Appl Environ Microbiol 58, 911-915.

Reed, D. J., Babson, J. R., Beatty, P. W., Brodie, A. E., Ellis, W. W. \& Potter, D. W. (1980). High performance liquid chromatographic analysis of nanomole levels of glutathione, glutathione disulfide, and related thiols and disulfides. Anal Biochem 106, 55-62.

Roberts, R. B., Abelson, P. H., Cowie, D. B., Bolton, E. T. \& Britten, R. J. (1955). Sulfur metabolism. In Studies of Biosynthesis in Escherichia coli, pp. 318-405. Edited by R. B. Roberts, D. B. Cowie, P. H. Abelson, E. T. Bolton \& R. J. Britten. Washington, DC: Carnegie Institute of Washington.

Seitz, A. P., Leadbetter, E. R. \& Godchaux, W., III (1993). Utilization of sulfonates as sole sulfur source by soil bacteria including Comamonas acidovorans. Arch Microbiol 159, 440-444.

Sörbo, B. H. (1955). Rhodanese. Metbods Enzymol 2, 334-337.

Thurnheer, T., Köhler, T., Cook, A. M. \& Leisinger, T. (1986). Orthanilic acid and analogues as carbon sources for bacteria: growth physiology and enzymic desulfonation. J Gen Microbiol 132, 1215-1220.

Thurnheer, T., Zürrer, D., Höglinger, O., Leisinger, T. \& Cook, A. M. (1990). Initial steps in the degradation of benzene sulfonic acid, 4-toluene sulfonic acid and orthanilic acid in Alcaligenes sp. strain O-1. Biodegradation 1, 54-63.

Uria-Nickelsen, M. R., Leadbetter, E.R. \& Godchaux, W., III (1993a). Sulfonate utilization by enteric bacteria. J Gen Microbiol 139, 203-208.

Uria-Nickelsen, M. R., Leadbetter, E. R. \& Godchaux, W., III (1993b). Sulfonate-sulfur assimilation by yeasts resembles that of bacteria. FEMS Microbiol Lett 114, 73-78.

Wanner, U. \& Egli, T. (1990). Dynamics of bacterial growth and cell composition in batch culture. FEMS Microbiol Rev 75, 19-44.

Ward, D. M. \& Winfrey, M. R. (1985). Interactions between methanogenic and sulfate-reducing bacteria in sediments. $A d v$ Aquat Microbiol 3, 141-179.

Zürrer, D., Cook, A. M. \& Leisinger, T. (1987). Microbial desulfonation of substituted naphthalenesulfonic acids and benzenesulfonic acids. Appl Environ Microbiol 53, 1459-1463.

Received 12 March 1996; accepted 28 March 1996 